\title{
A LINGUAGEM DE ÓRGÃO ESQUIZOFRÊNICA E O PROBLEMA DA SIGNIFICAÇÃO NA METAPSICOLOGIA FREUDIANA
}

\section{The schizophrenic organ-speech and the problem of meaning in the Freudian metapsychology}

Fátima Caropreso ${ }^{1}$ Richard Theisen Simanke ${ }^{2}$

\section{Resumo}

No artigo metapsicológico sobre o inconsciente de 1915, Freud formula uma explicação metapsicológica da alteração da linguagem na esquizofrenia, a qual pode ser complementada por algumas hipóteses apresentadas em dois de seus textos iniciais: Sobre a concepção das afasias, de 1891, e Projeto de uma Psicologia, de 1895. Além de esclarecerem o mecanismo subjacente à chamada "linguagem de órgão" (Organsprache) esquizofrênica, esses dois textos nos revelam que a alteração da linguagem nesta patologia consiste em uma reto mada da significação originária das palavras. $\mathrm{O}$ objetivo deste artigo é discutir de que maneira esses textos inaugurais da obra freudiana aprofundam a explicação metapsicológica da linguagem de órgão esquizofrênica esboçada por Freud em 1915 e, no sentido inverso, como as características das alterações de linguagem próprias dessa forma de patologia podem lançar luz sobre as concepções freudianas sobre a natureza e a origem da significação.

Palavras-chave: Freud; Metapsicologia; Linguagem; Significação; Esquizofrenia.

1 Mestre em Filosofia e doutoranda no Programa de Pós-Graduação em Filosofia da Universidade Federal de São Carlos (UFSCar). E-mail: fatimacaropreso@uol.com.br .

2 Professor do Departamento de Filosofia e Metodologia das Ciências da UFSCar. Via Washington Luís, km 235. São Carlos - SP. Cx. Postal 676. CEP: 13565-905. E-mail: drts@power.ufscar.br .

Rev. Filos., v. 18 n.23, p. 105-128, jul./dez. 2006 


\section{Abstract}

In his paper on the unconscious, written in 1915, Freud formulates a metapsychological explanation of the schizophrenic organ-speech, which can be complemented with some hypotheses presented in two of his early works: On the conception of aphasia (1891), and Project for a psychology (1895). These texts not only clarify the underlying mechanism of organ-speech, but also show that the disturbances of schizophrenic speech consist in a restoration of the original meaning of the words. This paper intends to discuss how these early Freudian works specify the metapsychological explanation of schizophrenic speech sketched in 1915 and, conversely, how the characteristics of the speech troubles present in this mental disease can help to elucidate Freud's views on the nature and origins of meaning.

Keywords: Freud; Metapsychology; Speech; Meaning; Schizophrenia.

\section{Introdução}

Pode-se dizer que a relação entre corpo e linguagem é um problema rigorosamente inaugural na psicanálise freudiana, a partir do momento em que Freud se pergunta como e por que um tratamento verbal pode ser efetivo na cura de sintomas somáticos tais como os que se apresentam na histeria. Na medida em que essa cura passa essencialmente pela elucidação do sentido desses sintomas, o problema da significação se acrescenta naturalmente àquele das relações entre corpo e linguagem na teoria freudiana. Talvez uma das expressões utilizadas por Freud que ilustre de forma mais exemplar essa relação é a de "linguagem de órgão" (Organsprache), empregada em 1915 para descrever uma das características mais chamativas da linguagem esquizofrênica, a saber, sua referência direta e imediata ao corpo e as sensações que dele provêm. De fato, no artigo metapsicológico O Inconsciente (1915/1982), Freud apresenta a hipótese de que o "sistema inconsciente" é constituído pelas representações que nunca foram ou que, devido à repressão, deixaram de ser associadas a palavras. Tais representações são chamadas de "representações de coisa" (Sachvorstellungen). O pré-consciente seria constituído pelas "representações de objeto" (Objektvorstellungen), as quais consistiriam nas representações de coisa associadas às "representações de palavra" (Wortvorstellungen) correspondentes. Freud caracteriza, a partir disso, a linguagem esqui- 
zofrênica como uma linguagem em que o vínculo com as representações de coisa está ausente e, além disso, como uma linguagem que se refere predominantemente ao corporal. Nesse texto de 1915, no entanto, ele não esclarece qual seria a relação entre essas duas características da alteração de linguagem presente na esquizofrenia. O objetivo deste artigo é mostrar que algumas hipóteses apresentadas por Freud em dois de seus primeiros textos, Sobre a concepção das afasias (1891/ 1992) e Projeto de uma psicologia (1950/1987), tornam mais compreensível essa relação e nos permitem compreender que, na verdade, a alteração da linguagem na esquizofrenia consiste em uma retomada do significado originário das palavras. A partir disso, pode-se verificar como certas concepções iniciais de Freud sobre o problema da significação em geral - e sobre as significações da linguagem em particular - se fazem presentes e estão pressupostas nas explicações das características de certos fenômenos patológicos fornecidas a partir de elaborações metapsicológicas mais tardias. Seria possível ilustrar, assim, o modo como, em Freud, a reflexão metapsicológica fundamenta a abordagem clínica e como esta última, por sua vez, pode justificar a primeira, na medida em que demonstra a sua aplicabilidade na elucidação de mecanismos psicológicos específicos.

\section{A alteração da linguagem na esquizofrenia}

Ao longo dos artigos metapsicológicos de 1915, Freud se pergunta, em diversos momentos, sobre em que consistiria afinal a diferenciação entre uma representação consciente e uma inconsciente e sobre o que acontece efetivamente quando uma representação passa de um estado a outro; pergunta-se, enfim, se esta corresponderia a uma distinção "tópica" - isto é, se haveria duas inscrições de uma mesma representação em dois lugares distintos - ou se corresponderia a uma distinção "funcional", isto é, se tal diferenciação decorreria de dois modos de investimento diferentes de uma mesma representação. Ele tende, em algumas passagens, a aderir a essa segunda hipótese, mas acaba optando por uma terceira, na última seção do artigo metapsicológico sobre o inconsciente. Essa terceira hipótese, na verdade, não exclui a segunda - a da distinção funcional - mas a complementa e especifica. Nesse texto, ele conclui, a partir da observação das neuro-

Rev. Filos., v. 18 n.23, p. 105-128, jul./dez. 2006 
ses narcísicas ${ }^{3}$, que, enquanto a representação de objeto consciente abrange a representação de coisa mais a representação de palavra correspondente, a representação inconsciente se restringe apenas à representação de coisa. Diz Freud:

(...) acreditamos saber agora onde reside a diferença entre uma representação consciente e uma inconsciente. Elas não são, como acreditávamos, diversas transcrições do mesmo conteúdo em lugares psíquicos diferentes, nem diversos estados funcionais de investimento no mesmo lugar; a representação consciente abrange a representação de coisa mais a representação de palavra correspondente, e a inconsciente é a representação de coisa somente. O sistema Icc contém os investimentos de coisa dos objetos, que são os investimentos de coisa primários e genuínos; o sistema Prcc nasce quando essa representação de coisa é sobre-investida pelo enlace com as representações de palavra que lhe correspondem (1915/1982, p. 160)

Segundo Freud, esse sobreinvestimento da representaçãocoisa, decorrente da associação desta com a palavra, é que faria com que a excitação em estado livre fosse ligada, levando, assim, à substituição do processo primário pelo secundário. Por isso, as representações de coisa que não fossem associadas a palavras permaneceriam insuscetíveis de se tornarem conscientes e permaneceriam regidas pelo processo primário, enquanto aquelas que fossem associadas a palavras se tornariam suscetíveis de consciência e passariam a integrar os processos psíquicos secundários. As primeiras constituiriam o sistema inconsciente, e as segundas, junto com as palavras a elas associadas, constituiriam o sistema pré-consciente. A dis-

3 A expressão "neurose narcísica" foi introduzida correlativamente aos primeiros desenvolvimentos sobre o narcisismo e acabou por ser paulatinamente abandonada após a elaboração da segunda tópica, cujos desenvolvimentos permitiram a Freud pensar a patologia em termos de uma oposição entre neuroses e psicoses (esta última categoria incluindo quase tudo anteriormente descrito como neurose narcísica, com exceção da melancolia). Freud descreve quatro modalidades principais de neuroses narcísicas: a paranóia, a esquizofrenia, a melancolia e a confusão alucinatória (ver SIMANKE, 1994, p. 132-64). Nelas, o processo narcísico de desinvestimento das representações de coisa faria com que as representações de palavra se comportassem como aquelas, explicando assim as peculiaridades da linguagem nessas afecções e evidenciando a importância dessa distinção no estabelecimento das relações entre o inconsciente e 0 pré-consciente-consciente. 
tinção entre representações pré-conscientes e inconscientes seria, portanto, uma distinção entre dois modos de investimento de uma mesma representação, uma vez que a representação de coisa, ao ser sobreinvestida pela palavra - ou seja, ao ter sua excitação ligada passaria a fazer parte do pré-consciente. Mas ela não se limitaria a isso, pois a representação pré-consciente possuiria um componente a mais que a inconsciente: a representação de palavra. Essa hipótese de que é a associação com a palavra que torna possível a consciência de uma representação já estava presente no Projeto de uma psicologia (1950/1987) e no capítulo sétimo de A interpretação dos sonhos (1900/1982). Desde aquele primeiro texto, já era possível inferir que as representações insuscetíveis de consciência são aquelas que não chegam a ser associadas a palavras ou que, devido à repressão, têm o seu vínculo com a palavra bloqueado. Em O Inconsciente, Freud estaria apenas apresentando essa hipótese mais explicitamente.

Com esses elementos, Freud formula uma explicação metapsicológica para a alteração da linguagem na esquizofrenia, na última parte do artigo metapsicológico sobre o inconsciente. Na fase inicial desta patologia, haveria uma retirada do investimento tanto das representações de objeto conscientes e pré-conscientes como das representações de coisa inconscientes (ao contrário da repressão que atua na neurose, a qual atinge apenas o vínculo entre a representação de coisa e a representação de palavra). Os sistemas inconsciente e pré-consciente seriam ambos desinvestidos, e o investimento retirado seria direcionado ao eu, o que teria como conseqüência a restauração de um estado de narcisismo primitivo. Numa segunda etapa da doença, o eu se esforçaria em retomar os investimentos de objeto e o faria investindo primeiramente as representações de palavra para, por meio destas, tentar alcançar novamente as representações de coisa. Quando se trata da esquizofrenia, nessa fase da doença em que as representações de palavra estariam investidas, mas as representações de coisa não, a referência aos órgãos e às inervações corporais viria para primeiro plano na expressão da linguagem. Esta passaria a se referir, de forma muito mais incisiva e direta, ao corporal, se tornaria uma "linguagem de órgão" ou uma "linguagem hipocondríaca", como diz Freud. Além disso, na esquizofrenia, em vez da linguagem ser regida pelo processo secundário, como ocorre no funcionamento psíquico

Rev. Filos., v. 18 n.23, p. 105-128, jul./dez. 2006 
normal, ela estaria submetida ao processo psíquico primário. Em suma, as duas principais alterações da linguagem que caracterizariam a esquizofrenia seriam a referência ao próprio corpo e a submissão ao processo psíquico primário.

Freud menciona o exemplo de um caso de esquizofrenia que lhe havia sido relatado pelo médico vienense Victor Tausk, no qual se manifesta claramente essa peculiaridade da linguagem esquizofrênica. Uma paciente de Tausk, levada a sua clínica após uma desavença com seu amante, se queixa: "Os olhos não estão direitos, estão torcidos (verdreht)" (1915/1982, p. 156). Em seguida, a própria paciente esclarece essa sua afirmação, expondo uma série de reprovações contra o amante: ele é um hipócrita, um simulador (Augenverdreher, literalmente, um torcedor de olhos), ele torceu os seus olhos e, agora, ela tem os olhos torcidos; esses já não são mais seus olhos, ela vê o mundo agora com outros olhos, etc. Transparece aí a ausência do investimento das representações de coisa e a referência da linguagem ao corporal: a rejeição do objeto de amor se exprime, na linguagem, por uma série de recriminações que, por sua vez, dão a razão de ser das sensações corporais que se impõem à paciente. Mas a relação entre esses dois fatos não pode ser compreendida a partir desse texto de 1915: embora Freud procure relacionar essas alterações de linguagem à regressão narcísica que constitui o mecanismo da esquizofrenia, ele não dá nenhuma indicação de por que essa regressão deveria fazer do corpo a referência essencial da linguagem esquizofrênica; dito de outro modo, resta por elucidar a questão de por que o desinvestimento das representações de coisa inconscientes (os investimentos de objeto "originários e genuínos", como Freud os designa) deve conduzir à "linguagem de órgão" própria dessa afecção. Restaria por explicar ainda a relação entre esta e o investimento regressivo narcísico do eu, que constitui o mecanismo básico de toda a classe das neuroses narcísicas. Estas questões, no entanto, como já mencionamos, parecem poder ser esclarecidas a partir de dois textos inaugurais do pensamento freudiano: Sobre a concepção das afasias, de 1891, e Projeto de uma psicologia, de 1895. Vejamos, então, o que Freud desenvolve nesses textos que nos permite compreender melhor a perturbação da linguagem na esquizofrenia e os demais problemas a ela relacionados.

Rev. Filos., v. 18 n.23, p. 105-128, jul./dez. 2006 
A origem dos conceitos de representação de palavra e representação de objeto

Em Sobre a concepção das afasias (Freud 1891/1992), os conceitos de "representação de palavra" e "representação de objeto"4 aparecem pela primeira vez na obra freudiana. Em seus textos posteriores, esses conceitos são retomados várias vezes, mas Freud não os define com a mesma minúcia com que o faz nesse trabalho. Em 1891, ele é levado a formular um conceito de representação que se distancia em vários aspectos daquele que predominava na psicologia e na neurologia da época. Em suma, o que Freud realiza é uma revisão crítica de algumas das principais hipóteses vigentes sobre a neurologia e a patologia da linguagem, a qual acaba implicando também em uma crítica das concepções psicológicas a elas subjacentes e na formulação de um novo conceito de representação, com o qual ele passa a operar a partir de então ${ }^{5}$.

Segundo o que Freud propõe em 1891, toda representação seria o correlato psíquico de um processo cortical associativo, o qual corresponderia ao último estágio da reorganização da informação sensorial proveniente do mundo externo. Com essa hipótese, ele recusa a idéia, então predominante, de acordo com a qual a representação seria o correlato de um engrama ou de um conjunto de engramas corticais, os quais estariam contidos em células nervosas singulares e seriam constituídos passivamente, a partir da projeção sobre o córtex da excitação sensorial que alcançasse a periferia do sistema nervoso. Freud formula a hipótese de que a excitação sensorial sofre uma série de reordenações sucessivas, ao longo do percurso que a conduziria da medula ao córtex, reordenações estas que seriam determinadas por fatores funcionais do sistema nervoso. No córtex, elas dariam origem a um processo associativo, e este processo seria o correlato neural de uma representação. Portanto, em vez de ser algo estático, uma cópia do mundo, a representação seria sempre o correspondente dinâmico deste, que o recria segundo os princípios de organização próprios à função nervosa.

4 O que Freud chama de representação de objeto em Sobre a concepção das afasias corresponde ao conceito de representação de coisa mencionado no texto O Inconsciente. Nesse texto, como vimos, Freud chama de representação de objeto o par constituído pela representação de palavra e a representação de coisa a ela associada.

5 Para uma visão mais detalhada da crítica que Freud empreende à teoria localizacionista das afasias e de suas conseqüências para a noção de representação, ver Caropreso (2003).

Rev. Filos., v. 18 n.23, p. 105-128, jul./dez. 2006 
Nesse texto sobre as afasias, Freud mantém a identificação do psíquico com o consciente; ele sustenta que o fisiológico e o psíquico são "concomitantes dependentes" - noção esta formulada pelo neurologista inglês Hughlings Jackson - e que todo evento psíquico é consciente. Dessa forma, tanto a representação de palavra quanto a representação de objeto seriam sempre conscientes. Mas em que consistiriam tais representações?

Segundo Freud, a representação de palavra consistiria em um complexo associativo constituído por elementos acústicos, visuais, quirocinestésicos e glossocinestésicos. A primeira imagem a se constituir seria a acústica; em seguida, a imagem glossocinestésica (da fala); depois, a visual e, por último, a quirocinestésica (da escrita). Todas as imagens se associariam à imagem acústica; por isso, todas as atividades da linguagem dependeriam, ao menos inicialmente, dessa imagem, que desempenharia uma função organizadora na gênese da representação de palavra. Essa hipótese sobre a representação de palavra, esclarece Freud, foi desenvolvida a partir da observação das formas como a linguagem se desintegra em decorrência de lesões orgânicas que afetam a área da linguagem no cérebro e das indicações que estas podem fornecer sobre o processo de aquisição das capacidades lingüísticas.

A representação de objeto - que, como dissemos, corresponde ao que é chamado de "representação de coisa" no artigo metapsicológico sobre o inconsciente - consistiria também em um complexo associativo, mas este complexo não seria composto apenas por representações acústicas, visuais e cinestésicas, como a representação de palavra; outros tipos de imagens (olfativas, táteis, etc.) poderiam integrá-lo. Além de ser constituída por uma variedade maior de elementos sensoriais, a representação de objeto, ao contrário da representação de palavra, consistiria num complexo associativo aberto, isto é, um complexo sempre capaz de receber o acréscimo de novos elementos. Uma vez que as imagens acústicas, visuais e cinestésicas de uma determinada palavra se constituíssem e se associassem, não poderia, segundo Freud, haver novos elementos a serem acrescentados àquela representação; dito de outro modo, novas representações de palavra poderiam constituir-se e associar-se às anteriores, mas não seria possível que percepções diferentes da mesma palavra viessem a ser experienciadas: é nesse sentido que Freud afirma que a palavra, ao contrário do objeto, forma um "complexo fechado". Já com relação à representação de um objeto específico, sempre haveria a pos- 
sibilidade de que, por exemplo, percepções visuais de diferentes ângulos e perfis ou percepções tácteis de suas diferentes partes fossem experienciadas e, assim, acrescentassem novos elementos à representação. Essa possibilidade permanente de vir a ter novas impressões sensoriais de um mesmo objeto é o que, segundo Freud, nos levaria a crer que os objetos externos existem independentes de nós. Freud apóia essa última hipótese nas concepções de Stuart Mill. Em sua monografia sobre as afasias, ele diz:

A própria representação de objeto é também um complexo de associações composto por representações visuais, acústicas, tácteis, cinestésicas e outras. Segundo o ensinamento da filosofia, a representação de objeto não contém outra coisa; a aparência de uma "coisa", cujas "propriedades" nos são transmitidas por nossos sentidos, se origina somente do fato de que, ao enumerar as impressões sensoriais percebidas desde um objeto, deixamos aberta a possibilidade de que uma larga série de novas impressões sensoriais se acrescente à cadeia de associações (J. S. Mill). (FREUD, 1891/1992, p. 122)

A representação de palavra se associaria à representação de objeto sempre por meio do elemento acústico da primeira e, normalmente, a partir do elemento visual da segunda. Freud afirma que, ao menos no caso dos substantivos, é a representação de objeto que atribui significado à representação de palavra; contudo, em 1891, ele não chega a formular nenhuma hipótese sobre como as representações de objeto adquiririam seu significado. No entanto, no Projeto de uma psicologia escrito em 1895, mas publicado postumamente em 1950 - essa questão começa a ser esclarecida. O passo seguinte, portanto, é verificar o que Freud diz aí sobre o surgimento do significado das representações de objeto.

\section{O significado originário das palavras e dos objetos}

No Projeto de uma psicologia (1950/1987), Freud deixa de identificar o psíquico com o consciente. A consciência passa a ser pensada como algo restrito em relação ao campo da representação e como algo posterior em relação à constituição desta. Freud identifica o psíquico inconsciente com os processos nervosos que, em Sobre a concepção das

Rev. Filos., v. 18 n.23, p. 105-128, jul./dez. 2006 
afasias, eram considerados como sendo os concomitantes fisiológicos do psíquico e, assim, a representação, em vez de ser concebida como o concomitante psíquico de um processo cortical associativo, passa a corresponder ao próprio processo cortical. A consciência seria algo que acompanharia apenas uma pequena parte desse processo associativo que constituiria a representação.

Freud retoma a noção de representação de palavra, no Projeto..., para explicar a possibilidade da rememoração de uma representação. De acordo com o que ele propõe, antes da constituição das associações lingüísticas - tanto das associações que vinculam palavra e objeto quanto das que constituem a própria representação de palavra -, as representações de objeto não poderiam ser rememoradas: elas permaneceriam insuscetíveis de se tornarem conscientes pela via do pensamento normal. Com exceção da percepção, apenas por meio da alucinação os objetos poderiam se tornar conscientes. A associação com a palavra é que tornaria as representações de objeto suscetíveis de consciência pela via comum do pensamento. Freud argumenta que, uma vez que a consciência depende do despertar de "signos de qualidade", os quais surgiriam a partir das percepções - a partir dos investimentos do aparelho por excitações exógenas -, para que uma representação investida desde 0 interior do aparelho pudesse se tornar consciente - isto é, para que ela pudesse ser rememorada - seria preciso que uma percepção fosse produzida junto com o seu investimento. Ele, então, conclui que é a imagem cinestésica da representação de palavra que possibilita isso, pois o investimento de tal imagem conduz a uma inervação motora, por mínima que seja, a qual, como todo movimento, produziria uma percepção. Quando o investimento da representação de objeto seguisse para a imagem acústica da palavra e desta para sua imagem cinestésica, uma percepção seria produzida e, conseqüentemente, seria emitido um signo de qualidade associado ao investimento da totalidade desse complexo. Dessa forma, as representações de objeto poderiam ser rememoradas por intermédio das associações lingüísticas:

(...) se as imagens de recordação forem tais que uma corrente parcial possa ir de uma delas para as imagens acústicas e para as imagens motoras da palavra, então, o investimento das imagens de recordação é acompanhado de notícias de eliminação, que são os signos de qualidade, e que, em conseqüência, também são signos de consciência da recordação (FREUD, 1950/1987, p. 456) 
Em Sobre a concepção das afasias, como vimos, Freud afirmara que as representações de objeto é que atribuem significado às palavras, aos substantivos pelo menos, mas ele não considera o problema de como as primeiras adquiririam significado. No Projeto..., essa questão é formulada e uma hipótese explicativa é proposta: a de que, originariamente, para compreender o sentido de uma representação de origem externa, é necessário rastreá-la até um investimento corporal. Na fase inicial do "juízo" - do processo de reconhecimento dos objetos pela comparação entre objetos percebidos e rememorados -, este se empenharia em rastrear as percepções de origem exógena até investimentos oriundos do próprio corpo. Tal processo consistiria, portanto, em uma tentativa de encontrar um caminho que levasse das representações de objeto, constituídas no sistema de memória do aparelho neuronal (o que Freud denomina o sistema "psi" do manto) a partir da excitação proveniente do sistema perceptivo (sistema "phi"), até investimentos originados na parte do sistema de memória que estaria em contato direto com o interior do corpo (o chamado sistema "psi" do núcleo). Diz Freud:

O julgar, mais tarde um meio para reconhecer o objeto que talvez tenha importância prática, é, assim, em sua origem, um processo associativo entre investimentos oriundos do exterior e investimentos provenientes do próprio corpo, uma identificação entre notícias ou investimentos de "phi" e de dentro (FREUD 1950/1987, p. 429)

Essa relação, proposta por Freud, entre uma representação de objeto e uma sensação corporal representada no núcleo do sistema "psi", que lhe confere primariamente seu significado, se explica pelo papel que a teoria desenvolvida no Projeto de uma psicologia atribui às duas vivências fundamentais - a vivência de satisfação e a vivência de dor - na estruturação dos processos psíquicos, dos quais constituem as duas ordens de motivação fundamentais. Em outras palavras, todo processo de pensamento é, na origem, um processo voltado para o encontro (ou reencontro) do objeto de satisfação - o objeto cuja percepção assinalou o início da vivência de satisfação e cuja representação constitui-se desde então em objeto de desejo - e para a evitação do objeto hostil - aquele cuja percepção assinalou o início da vivência de dor e que se constituiu desde então em objeto da defesa psíquica. Deste modo, "objeto de desejo" e "objeto hostil" são as duas significações originárias de qualquer representação de objeto, das quais qualquer outra significa-

Rev. Filos., v. 18 n.23, p. 105-128, jul./dez. 2006 
ção deve denivar ${ }^{6}$. O critério para atribuir uma ou outra depende da sensação corporal, prazerosa ou desprazerosa, associada à percepção e, secundariamente, à rememoração da representação; mais precisamente, se o surgimento do objeto assinalou o fim ou o início de um estado percebido como desprazeroso. Na verdade, as coisas são um pouco mais complicadas, pois Freud reconhece que, de início, o pensamento não pode incluir representações desprazerosas ${ }^{7}$ : o encontro com uma representação pertencente à série que se origina na representação do objeto hostil ocasionaria uma liberação de afeto (desprazer) que apenas sinalizaria para o pensamento que aquele não é um caminho para reencontrar o objeto de desejo e que o processo associativo deve tomar outra direção. Esses desvios impostos ao pensar pelo cruzamento com as séries psíquicas derivadas da representação do objeto hostil configuram o que Freud chama de "perturbação do pensamento pelo afeto" que, quando se tratar dos derivados deste tipo específico de representação hostil que constitui o trauma psíquico, terá um papel importante na explicação da neurose que Freud extrai dessas considerações psicológicas gerais. Apenas o surgimento da linguagem e o surgimento do sistema de associações que a vincula às representações de objeto permitirão que o pensamento possa operar com representações que se remetem a experiências desprazerosas. Dito de outra maneira, apenas a linguagem irá permitir que o pensamento confira significado às representações hostis, concepção na qual podemos localizar um dos fundamentos metapsicológicos da cura psicanalítica e, talvez, as origens do conceito de elaboração (Bearbeitung ou Durcharbeitung) com que Freud trabalhará posteriormente.

Se, em sua origem, portanto, as representações de objeto adquirem significado a partir da sua associação com representações corporais (as representações dos estados internos do organismo, como Freud

6 Esta é a forma específica como se apresenta em Freud a concepção empirista - que ele, como vimos, compartilha com a Stuart Mill - segundo a qual o que designamos como objeto só pode consistir num conjunto de sensações, cuja correspondência a uma existência real e externa só pode ser resultado de uma inferência ou crença (GABBI Jr. 2003, p. 99).

7 Observe-se que isso diz respeito apenas ao funcionamento inicial do pensamento e, portanto, a um processo secundário, que pressupõe já a ligação da quantidade e a inibição pelo eu. O processo primário, por sua vez, no modo como as coisas estão colocadas no Projeto... e diferentemente da concepção que prevalecerá entre 1900 e 1920, não pode evitar investir as representações desprazerosas derivadas da vivência de dor (CAROPRESO, 2005). 
sustenta no "Projeto...") e se as representações de palavra adquirem significado a partir da sua associação com os objetos (tal como consta no ensaio sobre as afasias), pode-se inferir que, na esquizofrenia, quando as palavras passam a se referir diretamente ao corporal, elas estão, na verdade, resgatando o sentido originário das palavras. E isso ocorre justamente devido à retirada do investimento das representações de coisa. Na ausência do elo intermediário entre as palavras e as sensações corporais - isto é, das representações de coisa - , o vínculo entre as palavras e o corporal torna-se direto. As palavras passam a denotar diretamente as sensações corporais e, dessa forma, o sentido originário das palavras volta a transparecer.

O mecanismo da esquizofrenia é concebido por Freud como uma versão exacerbada da conversão histérica, mas, ao contrário dos sintomas histéricos, os sintomas esquizofrênicos não apresentam um caráter simbólico ou de formação substitutiva (SIMANKE, 1994). Na histeria, os investimentos das representações de coisa persistem; é o vínculo destas com palavras que se encontra inacessível. Os sintomas conversivos surgem, então, no lugar das palavras ausentes, isto é, surgem como símbolos das representações de coisa reprimidas, no sentido em que Freud, na segunda parte do "Projeto...", fala de uma formação patológica de símbolos na neurose - do sintoma como um símbolo do trauma, mas um símbolo do qual o sujeito perdeu a referência da coisa que ele simboliza. É justamente essa intermediação da coisa que não existe na esquizofrenia e, nessas circunstâncias, as palavras passam a se referir diretamente ao corporal. Nesse caso, não há relação simbólica, as palavras manifestam diretamente o seu significado originário: encontram-se literalizadas, e o seu significado, fica claro então, está sempre, em última instância, relacionado ao corporal. Essa relação originária entre a linguagem e as sensações corporais é afirmada também por Gabbi Jr., que observa como ela se manifesta também nos sonhos. Após comentar a mesma passagem dos "Estudos sobre a histeria" mencionada abaixo, o autor acrescenta:

Freud sugere, assim, um momento na constituição das palavras em que elas tinham um sentido literal, ou seja, correspondiam literalmente a uma sensação corporal. (...) No sonho, como há um retorno a um estado primitivo do aparelho psíquico, as noções de objeto e de palavra retomam sua correspondência mais direta. Durante a vigília, as noções de palavras são transcrições que se tornaram tão metafóricas

Rev. Filos., v. 18 n.23, p. 105-128, jul./dez. 2006 
das sensações corporais, que não nos damos conta dessas características (GABBI Jr. 2003, p. 99) ${ }^{8}$.

Observe-se que a descrição do sonho como fenômeno narcísico no Complemento metapsicológico à teoria do sonho (Freud 1917/1982) reforça a idéia de que essas concepções estão pressupostas na explicação das alterações de linguagem esquizofrênicas. Freud explicita essa idéia ao discutir, nos Estudos sobre a histeria, o papel da linguagem na sintomatologia histérica, naquilo em que ela aí se assemelha, mutatis mutandis, ao que ocorre na esquizofrenia. Ele afirma, ao se referir ao caso de Cäcilie, apresentado no fim do relato do caso de Elizabeth von R.

Ao tomar literalmente a expressão lingüística, ao sentir o "espinho no coração" ou a "bofetada", após uma desfeita tomada como um evento real, a histérica não está tomando liberdades com palavras, mas voltando a animar as sensações às quais a expressão lingüística deve sua justificação (...) Todas essas sensações e inervações pertencem à "expressão das emoções", que, como Darwin [1872] nos ensinou, consiste em desempenhos originariamente significativos e apropriados; por mais que hoje se encontrem, na maioria dos casos, debilitadas a tal ponto que sua expressão lingüística nos parece uma transcrição figurada, é muito provável que tudo isto, antigamente, fosse entendido literalmente. A histeria acerta quando restabelece para suas inervações mais intensas o sentido originário da palavra. (FREUD, 1895/1952, p. 250-51)

Então, ao passar a se referir ao corporal, a linguagem esquizofrênica estaria resgatando o significado originário das palavras, o qual permanece velado no funcionamento psíquico normal. Sendo assim, não é a patologia que atribui um sentido figurado às palavras; ao contrário, ela restabelece o sentido literal destas, o qual se encontra obscurecido nos processos psíquicos normais do estado de vigília. Estes sim acabam atribu-

8 Deve ter ficado claro, pelo contexto, que nada disso tem qualquer relação com a conhecida tese lacaniana de que a linguagem psicótica se caracteriza por uma total incapacidade de metáfora (Lacan 1981, p. 91 e 247, por exemplo). Trata-se, em Lacan, de uma concepção totalmente diferente sobre a natureza da linguagem, na qual esta nada tem a ver, primariamente, com a significação, com a representação e, muito menos, com a nomeação de objetos e as sensações corporais. É a linguagem como estrutura formal e como um sistema de operações combinatórias entre significantes "puros" que Lacan vê manifestar-se exemplarmente na literalidade do discurso psicótico.

Rev. Filos., v. 18 n.23, p. 105-128, jul./dez. 2006 
indo um sentido figurado às palavras, na medida em que novos elos das séries associativas se intercalam e tornam cada vez mais distante a denotação originária da representação psíquica das sensações corporais.

\section{O obscurecimento do significado originário das palavras no funcionamento psíquico normal}

A forma como Freud concebe o processo de constituição das representações, em Sobre a concepção das afasias, fornece-nos uma pista para compreendermos por que, no funcionamento psíquico normal, esse significado originário das palavras e dos objetos permanece oculto e sua relação com o corpo torna-se indireta. Freud formula sua hipótese sobre o processo de constituição da linguagem, nesse texto, em oposição a uma hipótese sustentada pelo neurologista alemão Theodor Meynert. Segundo Meynert, a aquisição da linguagem consistiria em um processo de expansão topográfica. Haveria no córtex "lacunas funcionais" ou seja, áreas desprovidas de função - as quais iriam sendo preenchidas pelas imagens lingüísticas no decorrer da aquisição da linguagem. Dessa forma, os correlatos neurofisiológicos das palavras possuiriam cada um uma localização independente no córtex; com isso, os processos associativos seriam secundários e dependeriam da localização. Freud mostra a insustentabilidade dessas hipóteses de Meynert, argumentando que 0 modo como a linguagem se desintegra nas patologias orgânicas do sistema nervoso (isto é, nas afasias) não é compatível com essa concepção sobre o processo de aprendizagem e aquisição da linguagem. Se a hipótese de Meynert fosse correta, seria possível, no caso de uma lesão na área da linguagem, que apenas as representações localizadas na região da lesão fossem prejudicadas enquanto todas as demais permanecessem intactas e, com elas, os processos dos quais participam; seria possível, por exemplo, que a língua materna fosse prejudicada e uma outra língua, aprendida posteriormente, permanecesse intacta, ou que uma afasia sensorial (incapacidade de compreender a linguagem ouvida) ocorresse sem nenhum prejuízo da expressão pela fala. Mas isso nunca ocorre, observa Freud, como foi notado pelos próprios pesquisadores que sustentam essas idéias. A desintegração da linguagem, devido às alterações orgânicas do sistema nervoso, sempre produz uma "regressão funcional" que resulta num distúrbio global da atividade nervosa. Os elementos da

Rev. Filos., v. 18 n.23, p. 105-128, jul./dez. 2006 
linguagem sempre são prejudicados na ordem dos mais recentes para os mais antigos ou dos menos usados para os mais usados. Uma língua posteriormente aprendida sempre é afetada antes que a materna, a não ser que a primeira tenha sido mais utilizada que a segunda, exemplifica Freud.

Com base nessas observações e na crítica do modo como a noção de "lacunas funcionais" foi inferida, Freud conclui que a aquisição da linguagem deve consistir em um processo de "sobreassociação" (Superassoziation). Todas as representações de palavra se estabelecem na mesma área: na área da linguagem (Sprachegebiet), concebida como uma região cortical homogênea, onde tudo que ocorre é determinado pelas relações entre os processos, e não mais por diferenciações anatômicas. Essas representações associam-se umas às outras, ou melhor, se sobreassociam, na medida em que, segundo esse conceito, cada novo elemento acrescentado à cadeia associativa produz uma alteração na significação funcional do todo. Uma vez que as representações se sobreassociam, várias séries associativas se constituiriam, possuindo, como um todo, a mesma significação originária, a qual, no entanto, seria progressivamente encoberta pelas reordenações posteriores. Dessa maneira, para chegarmos ao significado primordial das palavras, seria preciso percorrer a série associativa no sentido inverso ao de sua constituição, até se alcançar a representação de objeto que elas originariamente nomeiam e, a partir desta, a representação corporal que estaria na base de toda a cadeia associativa ${ }^{9}$.

Freud se refere às representações de coisa do inconsciente, no artigo metapsicológico sobre o inconsciente, como os "investimentos de objeto primários e genuínos” (FREUD, 1915/1982, p. 160). Esses investimentos primários e genuínos talvez sejam aqueles correspondentes às representações de coisa primárias, mais diretamente ligadas ao corporal, as quais constituiriam a base das cadeias associativas. Podemos imaginar que, ao longo do processo de sobreassociação, o significado das palavras vai-se modificando, devido à influência dos novos vínculos associativos que se estabelecem, de maneira que esse significado originário, relacionado ao corporal, se dilui e permanece irreconhecível no proces-

9 É a esse trabalho que Freud denomina análise psíquica e, depois, psicanálise. O termo ideal dessa análise, mesmo que nunca atingido na prática, seriam as representações corporais que, nos artigos metapsicológicos de 1915, Freud passa a designar como "representantes de pulsão" (Triebrepräsentanzen).

Rev. Filos., v. 18 n.23, p. 105-128, jul./dez. 2006 
so psíquico normal, voltando à tona, de forma particularmente visível, nos sonhos e em algumas das patologias psíquicas, como a histeria e a esquizofrenia, destacadas especialmente por Freud.

\section{Considerações finais}

Esses dois textos freudianos iniciais nos permitem, portanto, compreender por que, na esquizofrenia, o desinvestimento das representações-coisa tem como conseqüência que a linguagem torne-se "linguagem de órgão", como diz Freud em O Inconsciente. Esses textos esclarecem por que, na ausência das representações de coisa, as palavras passam a denotar sensações corporais e nos esclarecem também que essa referência ao corporal não é algo arbitrário ou acidental, mas sim uma retomada do sentido originário das palavras, o qual permanece oculto na normalidade, devido, provavelmente, à série de associações que vem a se sobrepor àquelas primordiais. Dessa forma, podemos compreender não apenas como a patologia retoma o significado originário das palavras, mas também por que esse significado originário é obscurecido no funcionamento psíquico normal.

Embora essas observações apontem para a permanência, em sua obra posterior, das concepções iniciais de Freud sobre a natureza e a significação da linguagem, uma série de questões fica ainda em aberto sobre o sentido destas últimas; algumas delas são mencionadas aqui, ainda que de forma muito preliminar e apenas como sugestão para desenvolvimentos futuros. Dois problemas se destacam: em primeiro lugar, o da relação entre essa regressão funcional da linguagem onírica e psicótica a uma denotação da representação psíquica de sensações corporais e o caráter narcísico do sonho e das psicoses; em segundo, se a teoria da significação que podemos encontrar em Freud efetivamente se restringe a essa concepção denotativa e, nesse sentido, nominalista que se pôde constatar até agora.

O primeiro ponto coloca em questão o sentido do conceito de eu na metapsicologia freudiana, já que o narcisismo secundánio do sono e da psicose significa um retorno dos investimentos de objeto para o eu. A pergunta é por que esse retraimento deve-se fazer acompanhar de um retorno das significações originariamente corporais da linguagem. Pergunta cuja resposta não pode deixar de levar em conta que, para Freud,

Rev. Filos., v. 18 n.23, p. 105-128, jul./dez. 2006 
o eu é, an tes de tudo - e sobretudo talvez - , um eu corporal. Sabemos que o conceito de eu, essencial desde os primórdios da teoria freudiana das neuroses no papel de pólo defensivo do conflito neurótico, recebe uma primeira formulação metapsicológica nas páginas do Projeto de uma psicologia, para depois desaparecer da tópica freudiana até o aparecimento da teoria estrutural do aparelho psíquico em $\mathrm{O}$ eu e o isso, impulsionado pelo desenvolvimento da teoria do narcisismo que o coloca de novo no centro da reflexão metapsicológica ${ }^{10}$. Nessa sua formulação inicial, o eu é definido como se constituindo a partir do investimento ou ocupação constante dos neurônios nucleares por quantidades endógenas resultantes das diversas operações metabólicas do organismo. Assim, quando Freud se pergunta quais fatores são necessários para modificar os processos primários da alucinação de desejo e da defesa reflexa, ele reconhece que é necessário postular uma organização psíquica ainda não descrita, mas pressuposta na abordagem anterior desses processos, daí concluindo:

Essa organização chama-se o "eu" e pode facilmente ser apresentada pela consideração de que, com regularidade, se repete a recepção de Qn's endógenas em determinados neurônios (do núcleo) e de que o efeito de facilitação decorrente daí resulta em um grupo neuronal cuja ocupação é constante e que corresponde, portanto, ao portador do armazenamento exigido pela função secundária. (FREUD, 1950/1987, p. 416)

O eu do "Projeto..." é, assim, na origem, um eu corporal, resultante da representação psíquica dos processos somáticos no núcleo do sistema "psi", que forma sua parte constante à qual vem se acrescentar partes variáveis, a partir do momento em que o eu passa a incluir seletivamente em si certas representações de objeto de origem externa que se formam no manto desse mesmo sistema, ao mesmo tempo em que exclui outras - processos que, em 1923, Freud descreverá como a constitui-

${ }_{10}$ As razões para esse ostracismo provisório do conceito de eu são várias. Podemos apontar, em primeiro lugar, as dificuldades, à época do Projeto..., em formular uma teoria da gênese do eu, que só começaria a tomar sua forma definitiva com a introdução do conceito de narcisismo. Mas também, como se verá a seguir, o eu do Projeto... está estreitamente vinculado à dimensão pulsional do psiquismo - à representação psíquica das excitações somáticas no núcleo do sistema "psi" - a qual também deixa de ser representada no esquema da tópica a partir de A interpretação dos sonhos, para retornar apenas em 1923, com o conceito de isso (Es).

Rev. Filos., v. 18 n.23, p. 105-128, jul./dez. 2006 
ção do eu a partir do isso (Es) pelo contato com a realidade e como repressão, respectivamente. De fato, embora a reabilitação do conceito a partir da proposição da teoria do narcisismo não tenha feito referência explícita à natureza corpórea originária do eu, essa característica é explicitamente reconhecida no momento em que o eu é oficialmente reintegrado à tópica freudiana, em 1923. Quando, em O eu e o isso, Freud está empenhado em afirmar a origem do eu a partir da percepção - em outras palavras, a partir do contato entre o isso (Es) e a realidade -, ele observa como o corpo próprio é, ele mesmo, uma fonte de percepções internas e externas, participando por isso decisivamente da gênese do eu. Uma vez introduzido, esse fator complementar é imediatamente trazido para o primeiro plano: "O eu é, antes de tudo, um eu corporal; ele não é apenas um ser de superfície, mas sim, ele mesmo, a projeção de uma superfície" (FREUD 1923/1982, p. 294). E, a seguir, em uma nota de rodapé acrescentada à edição inglesa:

Isto é, o eu é, em última instância, derivado de sensações corporais, principalmente daquelas provenientes da superfície do corpo. Ele deve ser considerado, então, como a projeção mental da superfície do corpo, além de representar, como vimos acima, a superfície do aparelho psíquico (FREUD, 1923/1982, p. 294, n. 2) ${ }^{11}$

11 Mais adiante ainda, Freud acrescenta: "É como se, deste modo, nos fosse demonstrado o que dissemos há pouco sobre o eu consciente: que ele é, antes de tudo, um eucorpo (ein Körper-Ich)" (Freud 1923/1982, p. 295). Essa afirmação abre uma via para que se possa pensar a relação entre a natureza originariamente corporal do eu e 0 surgimento da consciência. Um ponto de vista semelhante, embora desenvolvido sem nenhuma referência a Freud, pode ser encontrado no livro de António Damásio sobre o problema da consciência: "Cheguei à conclusão de que o organismo, conforme representado no interior do cérebro, é um provável precursor biológico daquilo que finalmente se torna o elusivo sentido do self. As raízes profundas do self complexo que abrange a identidade e a individualidade encontram-se no conjunto de mecanismos cerebrais que, de modo contínuo e inconsciente mantém o estado corporal dentro dos limites estreitos e na relativa estabilidade requeridos para a sobrevivência. Esses mecanismos representam continuamente, de modo inconsciente, o estado do corpo vivo, em suas numerosas dimensões. Denomino proto-self o estado de atividade no conjunto desses mecanismos, o precursor inconsciente dos níveis do self que aparecem em nossa mente como os protagonistas conscientes da consciência: self central e self autobiográfico" (DAMÁSIO, 2000, p. 41-42, grifos do autor).

Rev. Filos., v. 18 n.23, p. 105-128, jul./dez. 2006 
Daí que a retração narcísica dos investimentos dos objetos para o eu resulte em que a linguagem torne a denotar diretamente as representações do corpo e de suas afecções, na medida em que é exatamente nisso que consiste o núcleo do eu para o qual os investimentos psíquicos são direcionados nos estados narcísicos. Dessa maneira, seria possível conciliar e integrar numa formulação conceitual única as diversas características atribuídas por Freud à esquizofrenia em 1915: o abandono dos investimentos objetais, o investimento narcísico do eu e o ressurgimento das significações literalmente corporais na Organsprache esquizofrênica.

O segundo ponto - isto é, se a teoria freudiana se limita a pensar a origem das significações da linguagem numa operação denotativa de nomeação de objetos - requer uma elaboração mais extensa e será abordada muito preliminarmente aqui com o único intuito de apontar algumas direções de reflexão. Gabbi Jr. (2003, p. 100), de fato, considera que, da teoria dos nomes de Stuart Mill, Freud teria retido tão somente sua concepção sobre as funções denotativas da linguagem, desconsiderando a possibilidade de que as palavras possam também significar conotativamente, o que significaria uma recusa em incluir as propriedades dos objetos no elenco das coisas nomeáveis ou, em sentido inverso, uma recusa de que os adjetivos possam ser nomes. Seria esse o sentido da afirmação de Freud, em Sobre a concepção das afasias, de que a palavra adquire seu significado por meio de sua ligação com a representação de objeto, "pelo menos se limitamos nossa consideração aos substantivos" (FREUD, 1891/1992, p. 122). Mas talvez essa afirmação possa ser interpretada numa outra direção, a saber, que a restrição colocada por Freud quer dizer que a relação da representação de objeto com a representação de palavra que a nomeia é apenas uma parte do problema da significação (o que se refere à significação dos substantivos), devendo os demais aspectos do problema ser resolvidos de outras maneiras, que não são explicitadas, mas que talvez possam ser inferidas do modo como a linguagem e a representação em geral são tratadas em outras partes da obra de Freud.

A idéia que propomos aqui - a título de conclusão e como um programa para futuras investigações - é que a operação pela qual a representação de palavra se vincula à representação de objeto (a nomeação propriamente dita) talvez seja apenas a parte mais visível do processo de constituição da significação, a "ponta do iceberg", por assim dizer. Ela pressuporia toda uma outra série de operações que aí per- 
manecem implícitas, mas que poderiam ser explicitadas a partir de desenvolvimentos teóricos encontráveis nesse e em outros trabalhos de Freud. Essas operações seriam as seguintes:

1) O processo de constituição da representação de palavra, descrito por Freud em Sobre a concepção das afasias, quando analisa o processo de aquisição da linguagem tendo por eixo o conceito de sobreasso ciação, e no Projeto de uma psicologia, quando discorre sobre a função secundária de comunicação que adquire o choro reflexo do recém-nascido, a importância que a partir daí adquire a imitação da fala do próximo, entre outras questões.

2) O processo de constituição da representação de objeto, delineado já no ensaio sobre as afasias e desenvolvido, do Projeto... em diante, em quase todos os momentos em que o problema do objeto se coloca, aí incluído o modo como a representação adquire primariamente sua significação mediante a conexão com as sensações corporais e o que Freud depois chamará de representantes de pulsão.

3) O estabelecimen to das relações das representações de palavra entre si, ou seja, o regime das relações formais da linguagem e da organização desta como um sistema, que talvez nunca tenha sido problematizado explicitamente por Freud, mas parece pressuposto no modo como explora as relações verbais em suas análises de lapsos, chistes, sintomas e sonhos (é claro que, para reconhecer a importância desse aspecto, não é necessário transformar Freud num protoestruturalista, como já se ressalvou acima).

4) O estabelecimen to das relações das representações de objeto entre si, em outras palavras, os princípios que presidem à formação das associações de objeto, já mencionadas em Sobre a concepção das afasias. De certa forma, todos os princípios associativos (simultaneidade, contigüidade, causalidade, etc.) que regem a formação dos diversos sistemas mnêmicos com que Freud opera de 1896 em diante podem ser considerados como modos de constituição das representações de objeto.

5) Finalmente, a associação en tre a representação de palavra e a representação de objeto, ou seja, a operação descrita em 1891 no último capítulo do ensaio sobre as afasias. O surgimento desse nexo arremataria todo esse processo, se consideramos a linguagem como princípio formal de organização do sistema pré-consciente e o modo como Freud, em 1915, passa a denominar representação de objeto ao

Rev. Filos., v. 18 n.23, p. 105-128, jul./dez. 2006 
complexo formado pela representação de coisa mais a representação de palavra, como se viu acima ${ }^{12}$.

Em suma, talvez a consideração das implicações de todas essas operações inter-relacionadas e do modo como concorrem para a constituição de um sistema psíquico capaz de linguagem possa dar um aspecto menos simplista à concepção freudiana da significação e tornar compreensível como, de um conjunto originário de significações corporais, podem-se derivar todas as complexidades do fenômeno lingüístico, além de fazer justiça ao uso criativo que a psicanálise freudiana faz da linguagem, tanto na prática terapêutica, quanto na explicação dos mais diversos acontecimentos psíquicos, individuais e socio culturais.

\section{Agradecimentos}

Fátima Caropreso agradece o apoio da CAPES ao seu projeto de doutorado, desenvolvido no PPG em Filosofia da UFSCar, ao qual o presente trabalho encontra-se relacionado. Richard Theisen Simanke agradece ao CNPq pelo apoio concedido, sob a forma de Bolsa de Produtividade em Pesquisa, ao projeto Consciência e representação em psicanálise: alcance e limites da reflexão metapsicológica, ao qual também se relaciona o artigo aqui apresentado.

${ }^{12}$ Observemos que, para Freud, o problema da significação e o problema da consciência (pelo menos da consciência mediata dos processos internos) são rigorosamente simétricos, se não dois lados de um mesmo problema: se, em Sobre a concepção das afasias, Freud estabelece que o significado depende da relação entre a representação de palavra e a representação de objeto, desde o Projeto... em diante, irá defender a idéia de que a consciência do pensamento e a rememoração dependem da relação da representação de objeto com as representações de palavra. Não é impossível que considerar significação e consciência como dois aspectos de um mesmo processo ou de uma mesma relação possa se constituir no ponto de partida para uma teoria mais geral da consciência, fundamentada em certas concepções da metapsicologia freudiana. 
Referências

CAROPRESO, Fátima. O conceito freudiano de representação em "So bre a concepção das afasias": Paidéia. Cadernos de Psicologia e Educação, v. 13, n. 25, p. 13-26, 2003.

. Compulsão à repetição: do "Projeto..." ao "Além do princípio do prazer". In: CONGRESSO INTERNACIONAL DE FILOSOFIA DA PSICANÁLISE. 2005, São Paulo. Anais... São Paulo, 2005. (in press).

DAMASIO, António. 0 mistério da consciência. São Paulo, SP: Companhia das Letras, 2000.

FREUD, Sigmund; BREUER, Joseph. Studien über Hysteria. In: SIGMUND, Freud. Gesammelte Werke: Ersten Band. London: Imago, 1895/1952. p. 75-312.

FREUD, Sigmund. Zur Auffassung der Aphasien: eine kritische Studie. Frankfurt: Fischer, 1891/1992.

. Die Traumdeutung. In: FREUD, Sigmund. Studienausgabe, Band II. Frankfurt: Fischer, 1900/1982.

. Das Unbewusste. In: FREUD, Sigmund. Studienausgabe, Band III. Frankfurt: Fischer Taschenbuch, 1915/1982, p.119-164.

. Metapsychologische Ergänzung zur Traumlehre. In: FREUD, Sigmund. Studienausgabe, Band III. Frankfurt: Fischer, 1917/1982. p. 175-191.

. Das Ich und das Es. In: FREUD, Sigmund. Studienausgabe, Band III. Frankfurt: Fischer , 1923/1982. p. 273-330.

. Entwurf einer Psychologie. In: FREUD, Sigmund. Gesammelte Werke: Nachtragsband. Frankfurt: Fischer, 1950/1987. p. 387477.

GABBI Jr, Osmyr F. Notas a projeto de uma psicologia: as origens utilitaristas da psicanálise. Rio de Janeiro, RJ: Imago, 2003.

Rev. Filos., v. 18 n.23, p. 105-128, jul./dez. 2006 
LACAN, Jacques. Le séminaire livre III: les psychoses. Paris: Seuil, 1981.

MEZAN, Renato. Freud: a trama dos conceitos. São Paulo, SP: Perspectiva, 1982.

SIMANKE, Richard. T. A formação da teoria freudiana das psicoses. Rio de Janeiro, RJ: editora 34, 1994.

Recebido em/Received in: 10/09/2006 Aprovado em/Approved in: 25/09/2006 